\title{
The effects of twice and four times daily zidovudine on p24 antigenaemia in CDC stage II/III patients
}

\author{
S Gill, A Tang, M Cordery, B Spacey, G Kelly, N T Bateman, D Barlow
}

\begin{abstract}
Reduction of HIV p24 antigenaemia by zidovudine was investigated in 34 HIV antibodypositive, asymptomatic patients in a randomised, double-blind, placebo-controlled trial. Zidovudine was shown to lower p24 antigen levels as effectively when administered twice daily as when administered four times daily. Serum levels of p24 antigen varied little over 18 weeks in patients taking placebo.
\end{abstract}

\section{Introduction}

In the search for prognostic factors that influence progression of HIV disease, a retrospective study has shown that patients who express p24 antigen in serum and lose antibodies to $\mathrm{p} 24$ antigen have a poor prognosis and are at increased risk of progression to CDC Stage IV disease. ${ }^{1}$ Zidovudine has previously been shown to suppress p24 antigenaemia. ${ }^{23}$

In a recent multicentre trial ${ }^{4}$ of its use in asymptomatic patients, $500 \mathrm{mg}$ and $1500 \mathrm{mg}$ of zidovudine daily were compared with placebo. Both treatment regimes involved five oral doses each day at four hour intervals. In the United Kingdom, Wellcome now recommend a dose regime of $250 \mathrm{mg}$ qds of zidovudine and few studies have investigated alternative dosing schedules. de Wolf and co-workers ${ }^{5}$ have reported efficacy with a twice daily zidovudine regime, in combination with acyclovir, for maintenance of suppression of p24 antigen, but no studies have been reported of the use of this dosing frequency for the induction and maintenance of suppression of p24 antigen as part of a blinded, placebo-controlled study.

Department of GU Medicine, St Thomas' Hospital, London

$S$ Gill, D Barlow

Department of Virology and Thoracic Medicine, St Thomas' Hospital, London

A Tang, $M$ Cordery

Academic Department of GU Medicine, Middlesex

Hospital, London

G Kelly

Wellcome Research, Beckenham, UK

B Spacey, N T Bateman
The aims of the present study were to establish whether serum p24 antigen levels were reduced as effectively by a total of $1200 \mathrm{mg}$ zidovudine given twice daily (bd) or four times daily (qds), and whether any reduction could be maintained when the total dose was reduced to $800 \mathrm{mg}$ daily.

\section{Patients and methods}

Patients attending the HIV clinic at St Thomas' Hospital who were asymptomatic or who had persistent generalised lymphadenopathy (CDC stages II/III) and who expressed p24 antigen in their serum on at least two occasions within six months were eligible for the study. All patients gave their informed consent and the study was approved by the Ethics Committee at St Thomas'. We excluded patients: (1) with haematological or biochemical parameters outside the recommendations of the protocol, for instance, $\mathrm{Hb}<11 \mathrm{~g} / \mathrm{dl}$; serum creatinine $>180 \mathrm{~mol} / \mathrm{l}$, (2) who had received experimental/antiviral treatment in the preceding six months, (3) who were intravenous drug users on maintenance treatment.

Thirty six patients were enrolled, but two patients withdrew from the study, one during the two-week run-in period and the second at week 0 . The remaining patients comprised 32 homosexual men, one heterosexual female contact of an intravenous drug user and one heterosexual contact of an African female. The mean age was 32.8 years (S.E. 1.6) and mean weight $67 \cdot 7 \mathrm{~kg}$ (S.E. 1.5).

The 34 patients were randomised into three groups and were given identical unmarked $100 \mathrm{mg}$ capsules containing placebo (12 patients) or zidovudine, $1200 \mathrm{mg}$ in divided doses for six weeks, followed by $800 \mathrm{mg}$ for six weeks (table 1). All patients were treated double-blind throughout the period of the study which included three weekly pre-treatment assessments, 12 weeks of medication, and assessments two and four weks after finishing treatment.

Patients were seen weekly for the first nine weeks and fortnightly thereafter. Haematological, biochemical and virological (p24) parameters were measured at each attendance and $T$ cell subsets monthly by fax analysis. Values of p24 antigen (ELISA, Abbott), CD4 counts and haemoglobin for each subgroup before treatment are given in table 2 . 
Table 1 Treatment regimens

\begin{tabular}{ll}
\hline Weeks 0-6 & Weeks $7-12$ \\
\hline Group A - AZT $600 \mathrm{mg}$ bd $\mathrm{n}=11$ & $400 \mathrm{mg}$ bd \\
Group B - AZT $300 \mathrm{mg}$ qds $\mathrm{n}=11$ & $200 \mathrm{mg}$ qds \\
Group C - Placebo 6 caps bd $\mathrm{n}=12$ & 4 caps bd \\
or 3 caps qds & or 2 caps qds \\
\hline
\end{tabular}

\section{Statistical methods}

We used a repeated measurement method to analyse the data ${ }^{6}$ since response to treatment was measured several times before, during and after its administration, the intention being to compare treatments with respect to trends in their effects over time as well as with respect to their mean levels of response. A standard analysis of variance is not appropriate as measurements are correlated over time. Instead, approximations have to be used for testing various hypotheses about the time factor.

\section{Results}

\section{p24 antigen levels}

The figure displays mean p24 antigen levels at each week for each group. The initial p24 antigen levels varied considerably between the patients and for this reason we have used the percentage change from the mean of pre-treatment levels as our outcome measure.

The effect of zidovudine can be clearly seen over time, the mean percentage reduction from pre-treatment levels in the qds group being $51 \%$ (SEM 9.3) at week 6 and $45 \%$ (SEM 8.5) at week 12 . In the bd group, the mean percentage reduction was $60 \%$ (SEM 4.8) at week 6 and 48\% (SEM 7.2) at week 12. The reduction in $\mathrm{p} 24$ antigen levels that was induced at $1200 \mathrm{mg} /$ day was maintained in both treatment groups when the dose was reduced to $800 \mathrm{mg} /$ day at week 6 and analysis of variance of the combined treatment groups versus placebo was highly significant $(\mathrm{p}<0.0001)$.

There was no change in the mean p24 antigen level in the placebo group at weeks 6 and 12. There was a marked consistency in the repeated measurements of p24 antigen levels in the 12 placebo patients (mean $\mathrm{SD}$ of logged values $=0 \cdot 14$ ).

An analysis of variance of repeated measures was carried out on the weekly percentage p 24 reduction in

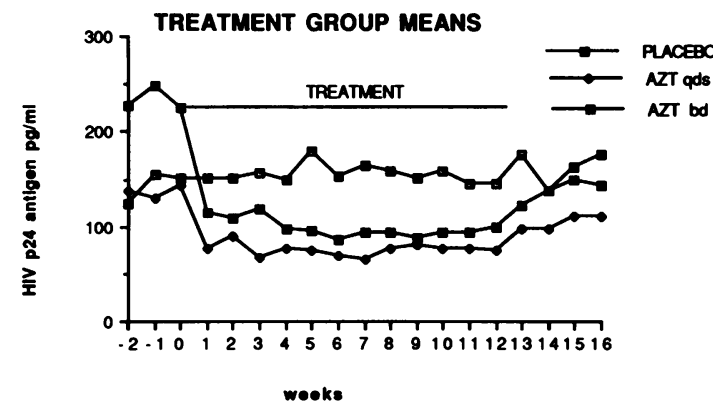

Fig Changes in p24 antigen over time.

the two active treatment groups. The $\mathrm{F}$ statistic ${ }^{\circ}$ for testing whether there were differences between the mean percentage p24 levels of response in the two groups was not statistically significant.

The sum of squares for time (which measures the degree to which a trend exists in the mean level of response) was significant $(p<0.001)$ using the Geisser and Greenhouse approximation to the $F$ statistic. There was no group by time interaction effect.

\section{CD4 counts}

There was no significant change in CD4 counts in any group during the study period. This finding contrasts with a recent report that noted an increase in the median CD4 count in mildly symptomatic patients taking $1200 \mathrm{mg}$ zidovudine daily as early as four weeks after commencing treatment. ${ }^{7}$

\section{Toxicity: haemoglobin}

After 12 weeks of treatment, the mean drop in $\mathrm{Hb}$ levels in the qds group was $1.59 \mathrm{~g} / \mathrm{dl}$ (S.E. 0.61). In the bd group, the mean fall in $\mathrm{Hb}$ was $1.72 \mathrm{~g} / \mathrm{dl}$ (S.E. 1.21 ) and in the placebo group, $0.56 \mathrm{~g} / \mathrm{dl}$ (S.E. 0.22 ). The difference in toxicity between the two treatment regimes with regard to anaemia was not statistically significant. Two patients required blood transfusion because of a fall in haemoglobin to $8 \mathrm{~g} / \mathrm{dl}$, or less, with symptoms. Both were in the qds group.

Pre-treatment $\mathrm{Hb}$ levels were $14.9 \mathrm{~g} / \mathrm{dl}$ and 15.8 $\mathrm{g} / \mathrm{dl}$ in these two patients falling to $8.0 \mathrm{~g} / \mathrm{dl}$ and 5.7 $\mathrm{g} / \mathrm{dl}$ respectively after eight weeks (NB: serum $B_{12}$ in both patients was within normal limits). The first

Table 2 Pre-treatment characteristics

\begin{tabular}{|c|c|c|c|}
\hline & $A(n=11)$ & $B(n=11)$ & $C(n=12)$ \\
\hline $\begin{array}{l}\text { Mean Hb (S.E.) } \\
\text { Mean CD4 (S.E.) } \\
\text { Median CD4 (range) } \\
\text { Mean p24 (S.E.) } \\
\text { Median p24 (range) }\end{array}$ & $\begin{array}{ll}14.6 & (0.4) \mathrm{g} / \mathrm{dl} \\
440 & (9 \cdot 0) / \mathrm{mm}^{3} \\
380 & (120-1000) \\
229 & (42 \cdot 4) \mathrm{pg} / \mathrm{ml} \\
212 & (64-502)\end{array}$ & $\begin{array}{ll}14 \cdot 3 & (0 \cdot 3) \\
490 & (5 \cdot 0) \\
500 & (270-820) \\
132 & (19 \cdot 1) \\
145 & (43-217)\end{array}$ & $\begin{aligned} 14 \cdot 8 & (0 \cdot 3) \\
480 & (6 \cdot 0) \\
420 & (250-940) \\
150 & (39 \cdot 4) \\
91 & (23-425)\end{aligned}$ \\
\hline
\end{tabular}


patient weighed $48 \mathrm{~kg}$ (against a group mean of $68 \mathrm{~kg}$ ) and this might explain some of the toxicity on a $\mathrm{mg} / \mathrm{kg}$ basis. ${ }^{8}$ Neither patient showed an increase in mean cell volume when on zidovudine-aplastic anaemia has been suggested as a possible mechanism. ${ }^{9}$ It is of interest that their initial CD4 counts were 0.47 and $0.43 \times 10^{9} / \mathrm{L}$ (group mean 0.49 ), which would not have singled them out as being at risk of toxicity prior to treatment.

\section{Side effects}

Headache (6 patients), nausea (5) and loss of appetite (4) were most commonly reported. These tended to occur in the first month of treatment and resolve thereafter as has been previously observed. ${ }^{10}$ No patient required dose reduction because of side effects. Of those reporting headache, one was taking placebo. All other side effects occurred in those on zidovudine. There was no difference in frequency of side effects between the two groups.

\section{Discussion}

The recommended daily regime for zidovudine was originally $1200 \mathrm{mg}$ divided into four hourly doses, on account of the short plasma half-life of the drug, ${ }^{11}$ a frequency of administration found inconvenient by many patients. This suggested a need for the investigation of the efficacy of less frequent dosing, as well as alternative total daily doses.

If serum p24 antigen levels reflect the level of viral replication and disease activity (a reasonable but unproven supposition), a drop in levels could provide a useful measurement of the efficacy of antiviral treatment. The total daily dose of zidovudine and its frequency of administration can be tested against this assumption as an alternative to measuring end-points such as disease progression, development of AIDS, or death. Changing serum p24 antigen levels may provide a more reliable short-term measure of response to treatment than CD4 counts because of the latter's variation in a given patient.

Different total daily doses of zidovudine have been investigated in patients similar to ours by Volberding et al $(500 \mathrm{mg} \text { and } 1500 \mathrm{mg})^{4}$ and Fischl et al $(1200 \mathrm{mg})^{7}$ in five times and six times daily doses respectively, and a reduction in p24 antigen levels was used as one of the outcome criteria in both studies.

We have shown that zidovudine $1200 \mathrm{mg}$ and $800 \mathrm{mg}$ is as effective in reducing serum p24 antigen levels when taken twice daily, as when taken four times a day in HIV antibody positive patients with CDC Stage II/III disease. In this study there was no evidence of increased toxicity with the bd dosage, although higher peak levels of zidovudine might be expected to result. Two patients out of $22(9 \%)$ treated with zidovudine required blood transfusions because of significant anaemia. Despite this, there was no significant difference between the two treatment regimes in haematological toxicity. Side effects were rare in both treatment groups.

The ability of zidovudine to suppress p24 antigen when administered 12-hourly suggests that its cellular half-life may be longer than its biological half-life of one hour. The maintenance of lowered p24 antigen levels following a reduction in daily dose from $1200 \mathrm{mg}$ to $800 \mathrm{mg}$ is compatible with the reported efficacy of $500 \mathrm{mg}$ daily in the treatment of early HIV disease. ${ }^{10}$

Serum p24 antigen levels showed little variation over 18 weeks in the 12 patients who were taking placebo (14 measurements per patient). This implies not only that the level remains fairly stable in a given patient, but that the method of measurement used is consistent and reproducible. This finding provides support for the use of the p24 antigen as level as a reliable criterion when measuring the outcome of treatment intervention.

Address for correspondence: Dr S Gill, James Pringle House, The Middlesex Hospital, London WIN 8AA, UK.

1 Lange JMA, Paul DA, Huisman $\mathrm{H}$, et al. Persistent HIV antigenaemia and decline of HIV core antibodies associated with transition to AIDS. BMJ 1986;293:1459-62.

2 Chaisson RE, Leuther MD, Allain J, et al. Effect of zidovudine on serum human immunodeficiency virus core antigen levels. Arch Int Med 1988;148:2151-3.

3 Jackson G, Paul DA, Faulk LA, et al. Human Immunodeficiency Virus (HIV) antigenaemia (p24) in the acquired immunodeficiency syndrome (AIDS) and the effect of treatment with zidovudine (AZT). Ann Int Med 1988;108:175-80.

4 Volberding $P$, Iagakos $S$, Koch $M$, et al. Zidovudine in asymptomatic human immunodeficiency virus infection ACTG 019. N Engl J Med 1990;322:941-9.

5 de Wolf F, Lange JMA, Goudsmit J, et al. Effect of zidovudine on serum human immunodeficiency virus antigen levels in symptom free subjects. Lancet 1988;i:373-6.

6 Fleiss JL. The Design and Analysis of Clinical Experiments. New York: Wiley, 1986.

7 Fischl M, Richmann D, Hansen N. The safety and efficacy of zidovudine (AZT) in the treatment of subjects with mildly symptomatic human immunodeficiency virus type I (HIV) infection. Ann Int Med 1990;112:727-37.

8 Balfour $\mathrm{HH}$, Chinnock BJ, Henry $\mathrm{K}$, et al. Update on pharmacodynamic and virological aspects of zidovudine. Satellite symposium at the IV International Conference on AIDS, Stockholm, June 1988.

9 Walker RE, Parker RI, Kovacs JA, et al. Anaemia and erythroporesis in patients with acquired immunodeficiency syndrome (AIDS) and Kaposi's sarcoma treated with zidovudine. Ann Int Med 1988;108:372-6.

10 Gelmon K, Montaner J, Fanning M, et al. Nature, time course and dose dependence of zidovudine related side effects: results from the multi-center Canadian Azidothymidine Trial. AIDS 1989;3:S55-S61.

11 Yarchoan R, Mitusya H, Myuers C, Broder S. Clinical pharmacology of $3^{\prime}$ azido, 2', 3'-Dideoxythymidine (zidovudine) and related dideoxysnucleosides. $N$ Engl $J$ Med 1989;321:726-38.

Accepted for publication 4 September 1990 